El presente estudio se centra en el análisis de la gestión del proyecto de traducción para el doblaje de la serie de ficción de producción francesa Profilage (Robert y Lebarbier, 20092015) y persigue una doble finalidad. Por una parte, describir el proceso de la traducción audiovisual (tav), tomando en consideración la interacción de los diferentes agentes del proceso con las fases del proyecto (Ferrer, 2011). Por otra parte, analizar las particularidades que presenta este proyecto de tav en la combinación francés-español, mediante el análisis de 5 temporadas que revelará normas de traducción presentes en el género crime procedural.

PALABRAS CLAVE: doblaje, series, estudios descriptivos, servicio profesional especializado, gestión de proyectos, profilage.

\title{
El doblaje de Profilage: Un estudio de caso
}

María R. FerRer

Universitat Jaume I, Castelló

Raduel Sanz

Universitat de València

\section{Dubbing of Profilage: A case study}

This paper focuses on the analysis of the management of the translation project for dubbing Profilage, a French fiction series (Robert y Lebarbier, 2009-2015). This study has two aims: first, to describe the process of Audiovisual Translation (AvT), taking into account the interaction of the different agents of the process with the phases of the project (Ferrer, 2011). Second, to analyse the peculiarities of this Avt project in French-Spanish combination by analysing 5 seasons of the mentioned series. This analysis will disclose translation rules present in the crime procedural genre.

KEY WORDS: dubbing, series, descriptive studies, specialized professional service, profilage 


\section{INTRODUCCIÓN}

Como ya señalaban Karamitroglou (2000), Mayoral (2002) y Chaume (2004), entre otros, sigue siendo urgente realizar estudios de las normas de la TAV en el plano del traductor como profesional, además del plano de la traducción como actividad, para lograr entender los detalles del proceso y no restringir el análisis a nociones impersonales y abstractas como «la adaptación» o «el ajuste», sino estudiar de cerca el trabajo de los profesionales que se ocupan de estas tareas y su incidencia en el proceso y en la traducción como producto (Richart, 20I2). Estaríamos pues hablando de «estudios sobre el traductor» y no sobre «la traducción»: una dimensión más concreta y tal vez con un corte sociológico de la actividad profesional de la traducción, pero sin duda interesante para llegar a una comprensión más profunda de las normas de la TAV en los últimos años. Uno de los defensores de esta metodología de investigación es Pym (2009: 32), que propone lo siguiente:

If the facts are wrong, they should be corrected. Yet if the ethical task of Translation Studies is to ultimately improve relations between cultures, and the task of translation history is to make narrative sense of those same relations between cultures, we require more than just raw data about texts, dates, places, and names. We must also be able to portray active people in the picture, and some kind of human interaction at work, particularly the kind of interaction that can string the isolated data into meaningful progressions.

Chesterman, ya en 2009, proponía dar un salto desde los Translation Studies a los Translator Studies:

[...] within the field of Translation Studies we may be witnessing the development of a new subfield, a new branch. I suggest we could call 
audiovisual), y pretende complementar, o dar una explicación a los estudios sobre normas en los que solo se analizan los datos concretos de varios productos determinados.

\section{OBJETIVOS DEL ESTUDIO}

Esta reflexión nace de una circunstancia poco habitual en el sector de la traducción audiovisual como es gestionar los proyectos desde una sociedad mercantil especializada, ya que el sector de la TAV es un sector en el que predomina la actividad de los traductores freelance (Ferrer, 20II). Dejando aparte las empresas de sonorización, que gestionan el proyecto integral, ejemplo, sociedades como Pink Noise, Traducciones Imposibles sl y Daruma sl funcionan de forma distinta a las clásicas agencias de traducción

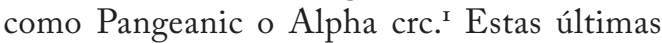
podrían llegar a trabajar en proyectos relacionados con la tav, aunque éste no fuera su ámbito de especialización, pero su labor se limitaría a subcontratar a un traductor audiovisual y gestionar el proyecto como uno más de su espectro habitual de encargos. Por todo ello, este trabajo plantea los siguientes objetivos:

I. Describir el proceso de la traducción de un proyecto audiovisual específico en el marco de la empresa especializada en TAV a principios del siglo xxI.

2. Analizar las fases del proyecto de traducción de una serie de ficción policiaca en la combinación lingüística francés-español.

3. Detectar tendencias en la traducción profesional de los diálogos específicos del género crime procedural en el contexto de la gestión

I Según la información que se desprende de sus respectivos sitios web: www.pinknoise.es, www.subbabel.es, www.traduccionesimposibles.com, www.pangeanic.com, www.alphacrc.com. de proyectos en una empresa especializada en TAV.

Para ello, se analizará la función e incidencia 151 de los agentes participantes en el proceso de trabajo en el texto de la serie Profilage, un ejemplo de ficción tv en una combinación de idiomas menos frecuente que lo que acostumbramos a ver desde hace unos años en las plataformas de vod que ofrecen crime procedurals. A lo largo del análisis veremos las distintas fases del proyecto y los roles, motivados en algunas ocasiones por la escasez de profesionales con un perfil adecuado. Este análisis macrotextual basado en la triangulación metodológica ${ }^{2}$ desvelará una serie de factores que condicionan la fase preliminar de una traducción audiovisual (Martí Ferriol, 2006: I04), que difícilmente se revelan en los análisis que se circunscriben al producto de la traducción. En un plano de análisis microtextual, se describirá una serie de estrategias que han determinado el resultado de la traducción a lo largo de las fases, atendiendo a la temática de la serie analizada. Se analizarán brevemente algunas de las dificultades a las que se enfrentó el equipo que conformaron traductoras y ajustadoras y las soluciones que se aportaron.

\section{CONTEXTUALIZACIÓN DEL PROYECTO}

Antes de pasar al capítulo de la metodología, es necesario contextualizar brevemente el escenario profesional en el que se desarrolla la actividad objeto de nuestro estudio. El proyecto analizado se enmarca en un contexto posterior

2 Este artículo retoma los aspectos más relevantes del análisis completo de la gestión de varios proyectos en empresas especializadas en TAV. Para realizar este análisis, se utilizó una metodología de corte descriptivo-exploratorio con triangulación de datos extraídos de encuestas y entrevistas (Ferrer, 20I6). 
a la crisis del sector de los servicios que afectó, entre otros, al de la traducción, entre los años 2009 y 2015 (Ferrer, 20I6: 13). En esos años, las empresas de traducción y localización se vieron obligadas a implementar los reajustes necesarios en infraestructura y plantilla para hacer frente a las nuevas exigencias del sector audiovisual. ${ }^{3}$ Esos reajustes comportaron una pérdida de terreno muy significativa frente a la presión del mercado, que dejo a los profesionales de la TAV en una situación desfavorecida, en la que carecían de herramientas de reivindicación de mejores condiciones, ya que sólo es posible competir en rapidez o precio pese a la leve recuperación actual en materia de horas de doblaje. Dada la dificultad de que, como profesionales independientes, los traductores freelance solucionen el problema de una industria que se aproxima a pasos agigantados a una producción masiva de traducción audiovisual, esto nos lleva a la hipótesis de que existe la necesidad de replantear los procesos de adaptación de productos audiovisuales que han predominado en el sector en los últimos años. Este replanteamiento supondría:

- Utilizar la especialización como herramienta de diferenciación profesional cualitativa, es decir, formar a profesionales con un perfil de traductor audiovisual que cubra las modalidades que el mercado demanda en la forma en que los clientes esperan.

- Rentabilizar los proyectos mediante el uso de nuevas tecnologías, tanto en doblaje como en subtitulación.

- Ofrecer soluciones integrales de localización en los nuevos productos de los que el traductor sabe más que el cliente y optimizar

3 De ahí que Red Comet Media, por ejemplo, decida en 2010 abrir un estudio de sonorización para poder ofrecer el proceso completo de localización de videojuegos y aplicaciones, incluyendo la sonorización. la cadena de valor: traducción y gestión de la sonorización, en el caso del doblaje.

Para poder llevar a cabo lo anterior sin que la empresa o el traductor freelance dejen de ser competitivos, una solución parece ser la unión del esfuerzo profesional en forma de cooperativas, estudios, asociaciones, etc.; o bien, la traslación de ese esfuerzo al marco de una infraestructura empresarial especializada en TAV (Ferrer, 20II), que pueda atender las necesidades de un sector en constante evolución.

Recurrir a la constitución de una sociedad mercantil de responsabilidad limitada, sin embargo, requeriría «habilidades relacionadas con la gestión de empresa» (Mayoral, 2002). Estas son, posiblemente, las que en el futuro tendrán que poner en práctica los profesionales de la traducción audiovisual; por tanto, parece conveniente poner de relieve las necesidades del proyecto de TAV tal y como se presenta en estas primeras décadas del siglo Xxi.

Hace ya más de ro años, Chaume (2004: 6I) planteaba un proceso de doblaje que se inicia con la compra del texto audiovisual (para su emisión en televisión en la cultura meta) y finaliza con la mezcla (compra, encargo de la sonorización completa a un estudio de doblaje, encargo de la traducción a un traductor, adaptación, doblaje, mezclas). Estas fases implican a determinados agentes como el traductor, el ajustador, el ayudante de producción, el director de doblaje y los actores, que en el contexto de este estudio dependen de empresas que se pueden agrupar en distintos niveles de la cadena de postproducción. Estos niveles muestran la jerarquía del sector audiovisual, que es relevante porque el enfoque de un proyecto y las decisiones y procedimientos que se adoptan en su desarrollo dependen en cierta medida de esta estructura. 
Tabla 1. La cadena profesional de la traducción y adaptación para el doblaje

CADENA DE PROFESIONALES

\begin{tabular}{ll}
\hline \multicolumn{1}{c}{ Cadena tradicional } & \multicolumn{1}{c}{ Nueva cadena } \\
\hline \multirow{2}{*}{ Traductor } & Traductor ajustador (TAJ)* \\
\cline { 2 - 2 } & Corrector (opcional) (CORR) / asesor lingüístico \\
\hline Ajustador & Ajustador (si el traductor sólo traduce) (AJ) \\
\hline $\begin{array}{l}\text { Ayudante de sala (pautado, marcado, marcaje, takeado } \\
\text { o takeo), cuando no lo hace el traductor o el ajustador }\end{array}$ & $\begin{array}{l}\text { Ayudante de sala (pautado, takeado o takeo) } \\
\text { (AYTE) }\end{array}$ \\
\hline Director de doblaje & Director (DIR) \\
\hline Actores de doblaje & Actores de doblaje (ACT) \\
\hline
\end{tabular}

Las siglas indicadas entre paréntesis se utilizarán posteriormente en el análisis de los proyectos

La tabla I representa la cadena de agentes que participan en los proyectos profesionales de doblaje según Ferrer (20I6: 5I). El análisis de Profilage revelará qué flujos de interacción se establecen entre estos agentes y cómo afectan al texto traducido en el caso de este proyecto en concreto.

- El traductor: un traductor que puede estar especializado o no y que se limita a traducir el guion, apoyándose o no en la imagen, dependiendo si dispone o no de ella. Este traductor, especialmente en el caso de los encargos para las grandes distribuidoras, entrega una traducción literal, conocida en inglés como rough translation (WhitmanLinsen, 1992).

- El ajustador: profesional del ajuste que puede ser también actor o director de doblaje, que no necesariamente es traductor ni tampoco necesariamente conoce la lengua de origen, pero sí es un experto en la lengua meta. Su función es acortar o alargar el texto para hacer que el ritmo se corresponda con el movimiento de la boca de los actores, marcar las entradas y salidas de encuadre y los diálogos de fondo, insertos y otros elementos que aparecen en la imagen, pero no siempre en el texto.

- El traductor adaptador (o traductor ajustador): es el traductor que traduce y adapta el texto directamente, teniendo en cuenta las restricciones de la imagen en su traducción, y aplica las normas del ajuste para trabajar la sincronía.

- El corrector: profesional perteneciente al equipo del cliente que se ocupa de dar su aprobación a la traducción realizada por su proveedor. Esta figura es más común en el ámbito del documental. En las grandes empresas de traducción audiovisual este corrector forma parte del proceso de control de calidad (QC, de las siglas de quality control en inglés), posterior al doblaje en sala.

- El ayudante de producción (o ayudante de sala): la persona encargada de formatear el guion traducido y ajustado y cortarlo en takes o tomas, la unidad de trabajo del actor de doblaje, para proceder después a confeccionar el gráfico de personajes e intervenciones y preparar la convocatoria. El formato de takes responde a un acuerdo establecido por 
el convenio de empresas del doblaje ${ }^{4}$ (Chaume, 20I2). Aunque en algunos casos puede ser modificado por cuestiones de presupuesto (un take doble es más económico que dos takes sueltos en días diferentes, ya que se paga una sola convocatoria); la convocatoria siempre se realizará con el objetivo de simplificar procesos y ahorrar gastos. En algunos casos, el traductor adaptador también pauta o marca, es decir, segmenta el texto en takes.

- El director de doblaje: profesional que se ocupa de la dirección artística de los actores de doblaje y les da instrucciones durante la grabación acerca del tono y la interpretación, ya que los actores no conocen los detalles del producto que están doblando y tampoco se dobla en orden cronológico de intervención en el filme (Chaume, 2004: 76). El director de doblaje ejerce muchas veces la función de ajustador, es decir, realiza ambas funciones.

- Los actores de doblaje: dan vida a la traducción y encarnan a los personajes de la pantalla, aunque, a diferencia de los actores de teatro, cine y televisión, no conocen de antemano el texto que van a interpretar y deben seguir la interpretación del actor original (ibid.).

\section{METODOLOGÍA}

Nuestro trabajo utilizará una metodología de corte descriptivo y exploratorio. El análisis del proyecto se basará en el modelo descriptivista de Karamitroglou (2000), que analiza la traducción como parte del sistema (literario) meta (target literary system). El autor dibuja un cuadro cartesiano en el que un eje lo ocupan los factores que afectan a la traducción audiovisual, es decir, los agentes humanos, los productos, los receptores

4 Véase: http://adoma.es/convenio/

y el modo audiovisual. El otro eje lo constituye el nivel de detalle del análisis, desde un análisis más general y macroscópico (upper level), hasta un análisis más particular y microscópico (lower level) pasando por un nivel intermedio (middle level). Con estos niveles, Karamitroglou pretende estudiar desde las fuerzas del mercado hasta la decisión de traducción de un producto concreto.

\section{Modelo de análisis}

Dado el carácter general y macrotextual del modelo de Karamitroglou, su aplicación al proyecto que nos interesa excedería los límites de esta investigación, por lo que hemos creído necesario adaptarlo y modificarlo de forma que dicha adaptación permita cotejar los datos relativos a los agentes del proceso con los pertenecientes a las fases del proyecto de TAV en el marco de la empresa de servicios de tav. En nuestro caso, estudiaremos los factores que inciden en el proceso, pero en lugar de cruzar dichos factores con el nivel de análisis, lo haremos con las diferentes fases del proyecto de traducción, de modo que seamos capaces de describir el papel e incidencia de dichos factores en cada una de las fases de un proyecto de TAV. ${ }^{5}$

Según las empresas consultadas, un proyecto se articula en torno a las fases de administración (ADMIN.), producción, administración y control de calidad y a lo largo de su gestión, operan las subfases y agentes que se aprecian en la tabla. Por lo tanto, la reflexión en torno al marco en el que se desarrolla el proyecto, a los agentes y factores que inciden en él y al traductor en concreto partirán de una serie de preguntas de investigación que surgen en el momento de analizar un servicio de traducción y su gestión en una empresa espe-

5 En la tabla 2 se mencionan tareas relativas a la localización de videojuegos, pero por restricciones de espacio, no se profundizará en ello a lo largo de estas páginas. 
Tabla 2. La TAV como actividad profesional en el marco de la empresa: fases y agentes

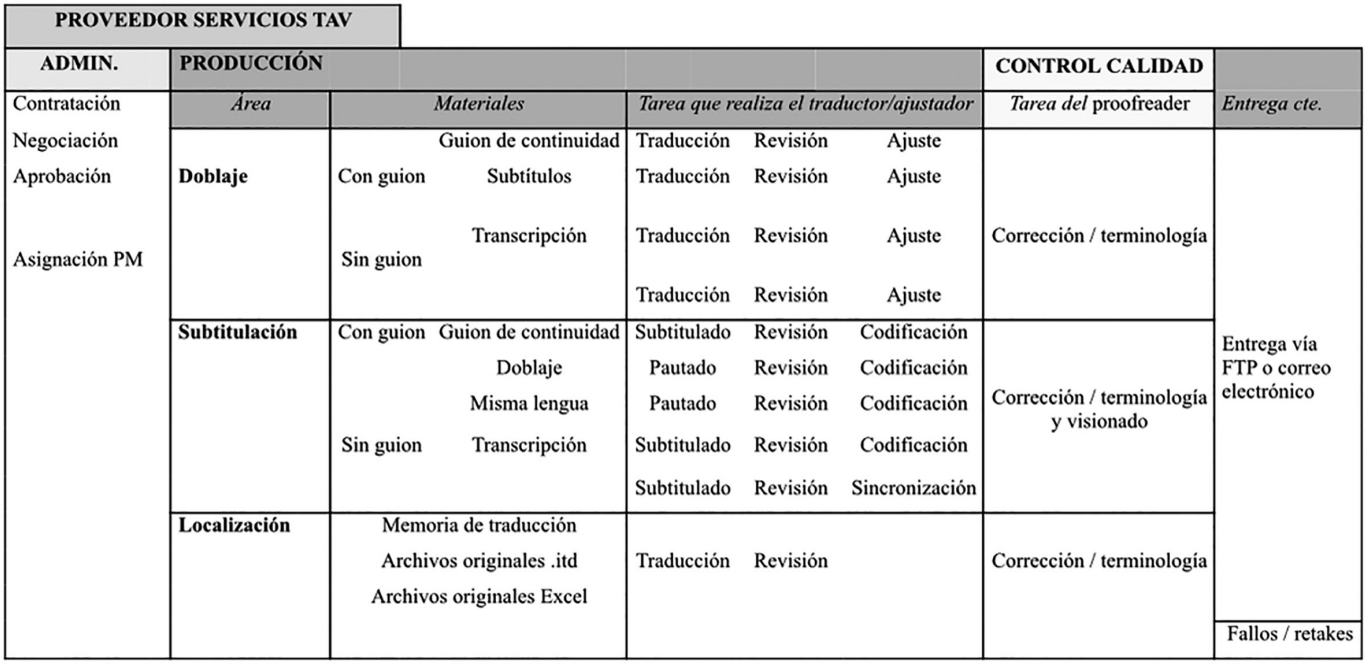

cializada (cuyo nombre no se consigna aquí por cuestiones de confidencialidad) dentro del contexto profesional específico que se ha descrito.

\section{Preguntas de investigación}

$\mathrm{Si}$, al fin y al cabo, como ya apuntó Hermans (I996: 26), toda traducción profesional se circunscribe en una transacción comercial y por lo tanto está supeditada a un marco económico y financiero que interacciona con la dimensión sociológica del traductor y de los agentes humanos, que son los que decidirán qué textos se traducen y cómo, es inevitable que ante la voluntad de analizar un proyecto de TAV, nos encontremos frente a las siguientes preguntas:

- ¿Cómo es el proceso de la traducción audiovisual en el marco de la empresa especializada en la industria actual de la tav? ¿Cuál es la incidencia de los agentes en el proceso actual de traducción audiovisual?

- ¿Cómo cambian los roles adoptados por los traductores audiovisuales en función del proyecto? ¿Son estos los nuevos perfiles que demanda el sector (un perfil ecléctico y adaptable)?

- ¿En qué consistió, en concreto, un proyecto representativo del género crime proc y de producción francesa como es Profilage, y qué nuevas exigencias profesionales se desprenden de ello?

\section{EL PROYECTO PROFILAGE}

El proyecto que hemos analizado es la serie Profilage en su totalidad, desde su planteamiento y sus fases preliminares hasta el control de calidad. Es representativo porque la afluencia de series de producción francesa que se traducen y adaptan es menor que la de series norteamericanas, por un lado; esto conlleva una menor disponibilidad de profesionales expertos, tal y como mencionó el estudio de doblaje encargado de la 
sonorización. Por otro lado, porque se considera un producto de importancia al emitirse en un canal nacional en el sistema meta ( $\mathrm{La} 2$ ).

156 Antes de pasar a describir los rasgos específicos de este proyecto, es conveniente realizar una breve sinopsis y presentar a los personajes principales.

Chloé Saint Laurent es experta en perfiles criminales y colabora con un cuerpo policial parisino en la investigación de casos de homicidio. Se caracteriza por ser dulce, llevar ropa muy colorida y por ocultar tras esa fachada llamativa una gran inteligencia y profesionalidad. Poco a poco irá encajando en el equipo, y sus compañeros, que se mostrarán al principio reservados, se convertirán en amigos verdaderos.

En cuanto a los personajes, el papel protagonista está representado por el personaje de Chloé Saint-Laurent. Es psicóloga especializada en criminología. Es compleja, sensible e intuitiva, y sabe ponerse en la piel de los asesinos y de sus víctimas. Será un activo muy valioso en el equipo al que está asignada desde el primer episodio.

Thomas Rocher es el agente de policía que dirige el equipo en la mayor parte de la serie (aunque esta comienza con otro personaje en su cargo), viudo, un hombre pragmático que no se prodiga en cortesías. Es taciturno y autoritario.

El inspector Lamarck es el responsable de que Chloé llegue a la brigada: la invita él a formar parte del equipo porque cree que la criminología ha evolucionado y que la policía debe adaptarse a una nueva manera de analizar los crímenes.

Hyppolite de Courtène y Frédérique Kancel son los otros dos agentes que constituyen la brigada de investigación criminal que dirige Rocher.

En cuanto a la gestión del proyecto, los rasgos por los que nos parece un producto adecuado para esta investigación son los siguientes:
- La traducción se realiza de francés a español, una combinación lingüística más complicada de encontrar entre los profesionales de la TAV hoy en día, según conversación con el estudio de doblaje, ya que existen más profesionales con combinación en-es que fr-es. ${ }^{6}$

- El formato es el de serie completa en lugar de producciones unitarias, un modelo de encargo según el cual se contrata la traducción de todas las temporadas o de un número global de episodios.

- El volumen es «masivo», es decir que obliga a un ritmo de producción elevado.

- La traducción se realiza entre varias personas, es decir, se trata de una traducción en equipo.

- El proceso de trabajo es específico de la infraestructura empresarial especializada en TAV (vid. tabla 3), que combina las competencias de traductores profesionales y de expertos en otras tareas adscritas al proyecto de traducción como la gestión de proyectos, desde la negociación hasta la planificación o el control de calidad, la facturación y la atención posventa.

El análisis revelará las pautas actuales del desarrollo de los proyectos de TAV en un contexto profesional específico y evaluará su incidencia en el producto final, lo cual nos permitirá comprender el tratamiento que se da a un encargo de este tipo en la traducción francés-español en el marco de los servicios especializados.

\section{RESULTADOS DEL ANÁLISIS}

En este apartado, partiremos de los dos aspec-

6 Simultáneamente a este proyecto, el cliente tuvo que subcontratar parte de otra serie francesa al mismo equipo profesional (Traducciones Imposibles, S.L.) ya que carecían de suficientes expertos en TAV y francés con un perfil adecuado para el encargo. 
tos principales del encargo que configuraron la naturaleza del proyecto: por una parte, las fases del mismo, y por otra, los agentes que intervinieron para su consecución. En un segundo momento, nos centraremos en los aspectos textuales que supusieron mayores dificultades para el equipo traductor y que exigieron de una coordinación indispensable para su resolución.

\section{El plano del encargo: las fases y los agentes}

En cuanto al proyecto, se desarrolló de una forma recurrente en el marco de la empresa especializada, a la que se presupone una enorme adaptabilidad a las necesidades del cliente: posibilidad de aumentar equipo, un ritmo de producción más elevado, paquete de servicio (toda la serie, traducción y ajuste) y precio ajustado (se exigió un descuento por volumen). En este caso además, debido a la proximidad de las vacaciones de verano, el proyecto se concentró en 2 meses y el ritmo de producción (5 episodios semanales) requirió una gran interacción entre los agentes para minimizar problemas y agilizar procesos, como la gestión de materiales (en lugar de usar el editor de guiones, se trabajó en Word y el departamento técnico convertía a Excel), que exigió cooperación por parte de todos y flexibilidad para alternar más carga de trabajo en semanas alternas.

En cuanto al itinerario, el proyecto pasó por todas las fases administrativas de forma lineal hasta llegar a la traducción y al ajuste, donde las subfases no fueron lineales debido al flujo de consultas entre traductoras, ajustadoras, directores y aplicación de cambios de criterio «sobre la marcha».

Se dieron dos incidencias en la asignación a equipos importantes para el proyecto:

I. Cambio de agentes: la única traductora ajustadora dejó de traducir para poder ajustar más cantidad de episodios a la semana con la calidad que se esperaba, pasando las traductoras a asumir más episodios semanales (3 y 2 por semana alterna). Se puede considerar una vuelta a la cadena de profesionales clásica.

2. La gestión del proyecto no se limita a una fase preliminar, sino que se entremezcla con la de traducción y con la del doblaje en sí: una vez entregada una traducción, el ajustador puede verse obligado a volver atrás para solucionar incoherencias (por trabajar dos traductoras con capítulos no consecutivos, o incluso tomar decisiones con desfase, por tratarse de episodios más avanzados o menos).

\section{El plano del texto}

\section{El traductor como eje de coherencia}

En cuanto al texto, destacamos que al mencionado alto ritmo de trabajo y la necesaria coordinación de todos los agentes intervinientes en la cadena de la traducción (en particular de traductoras y ajustadoras), había que añadir el nivel de tecnicidad de la serie analizada, para obtener un producto final adecuado a las expectativas del cliente y que además tuviera coherencia, es decir, «que sonara natural». Era indispensable que, a pesar de que en el producto final habían intervenido dos traductoras, dos ajustadoras $y$, finalmente, dos directores de doblaje, el espectador no percibiera las posibles diferencias que pudiera haber en cuanto a estilos de traducción o ajuste. Consensuar la terminología, avisar de la presencia de un personaje que ya había aparecido en otro capítulo o simplemente contar cómo iba desarrollándose la trama, fueron cuestiones que se abordaban a diario, por lo que la comunicación en el equipo fue constante durante todo el proyecto. Una de las curiosidades que caracterizó este proyecto fue la presencia de dos 
Tabla 3. Resumen del análisis de las fases de Profilage

\begin{tabular}{|c|c|c|c|c|c|}
\hline & & $\begin{array}{l}\text { Modo } \\
\text { audiovisual }\end{array}$ & Agentes & $\begin{array}{l}\text { Producto } \\
\text { (objeto de la fase) }\end{array}$ & Receptor ideal \\
\hline \multirow{3}{*}{ ADMIN. } & Presupuesto & \multirow{13}{*}{$\begin{array}{l}\text { Doblaje } \\
\text { para TV }\end{array}$} & Dirección & $\begin{array}{l}\text { Tarifa de paquete de } \\
\text { traducción y ajuste } \\
\text { por } 5 \text { temporadas. }\end{array}$ & \multirow{13}{*}{$\begin{array}{l}\text { Público } \\
\text { general }\end{array}$} \\
\hline & Aprobación & & Dirección & Acepta encargo. & \\
\hline & $\begin{array}{l}\text { Asignación } \\
\text { (sede) }\end{array}$ & & Dirección & $\begin{array}{l}\text { Proyecto in-house } \\
\text { para un mayor con- } \\
\text { trol. }\end{array}$ & \\
\hline \multirow{8}{*}{ PROD } & $\begin{array}{l}\text { Asignación } \\
\text { (equipos) }\end{array}$ & & $\begin{array}{l}\text { Project } \\
\text { Manager }\end{array}$ & $\begin{array}{l}\text { Reúne un equipo de } \\
3 \text { traductoras FR-ES } \\
\text { y } 2 \text { ajustadoras. }\end{array}$ & \\
\hline & $\begin{array}{l}\text { Gestión mate- } \\
\text { riales }\end{array}$ & & $\begin{array}{l}\text { Project } \\
\text { Manager }\end{array}$ & $\begin{array}{l}\text { Descarga de vídeos } \\
\text { vía ftp y envío de } \\
\text { guiones por } e \text {-mail. }\end{array}$ & \\
\hline & Planificación & & $\begin{array}{l}\text { Director } \\
\text { doblaje }\end{array}$ & $\begin{array}{l}5 \text { episodios sema- } \\
\text { nales. }\end{array}$ & \\
\hline & Traducción & & $\begin{array}{l}\text { Traductor } \\
\text { (AV) }\end{array}$ & $\begin{array}{l}\text { Se entrega texto en } \\
\text { Excel para uso del } \\
\text { cliente. }\end{array}$ & \\
\hline & & & FR-ES & $\begin{array}{l}\text { Criterios propios de } \\
\text { estilo. }\end{array}$ & \\
\hline & Ajuste & & Ajustador & $\begin{array}{l}\text { Ajustadoras con } \\
\text { formación especí- } \\
\text { fica en traducción } \\
\text { audiovisual. }\end{array}$ & \\
\hline & Revisión & & No & - & \\
\hline & VIsionado & & No & - & \\
\hline $\begin{array}{l}\text { CONTROL } \\
\text { CALIDAD }\end{array}$ & $\begin{array}{l}\text { Control } \\
\text { Calidad }\end{array}$ & & Ajustador & $\begin{array}{l}\text { Corrigen lenguajes } \\
\text { específicos tras } \\
\text { consultar con t de } \\
\text { formación jurídica. }\end{array}$ & \\
\hline POSTVENTA & $\begin{array}{l}\text { Correcciones } \\
\text { cliente }\end{array}$ & & $\begin{array}{l}\text { DIrector } \\
\text { doblaje }\end{array}$ & $\begin{array}{l}\text { Los directores de } \\
\text { doblaje especifican } \\
\text { sus preferencias des- } \\
\text { pués de las primeras } \\
\text { entregas. }\end{array}$ & \\
\hline
\end{tabular}


directores de doblaje, con ideas y gustos muy distintos respecto a lo que debía ser el producto final. Dados los conocimientos de francés de uno de los directores, este manifestó su interés por una versión más fiel, en el sentido de más pegada al texto origen que el otro, lo que condicionó el ajuste, y por tanto el producto final; el otro director prefería una traducción más libre, más natural, más acorde a lo que conocemos como «oralidad prefabricada» (Chaume, 2004). Este hecho determinó la organización del trabajo en equipo: se constituyeron dos grupos de trabajo, compuestos cada uno por una traductora y una ajustadora. Atendiendo a que los directores dirigían el doblaje de los capítulos pares o impares respectivamente, cada grupo de trabajo ajustaba el resultado de su traducción a los deseos de ese director en concreto. Sin embargo, y dado el acelerado ritmo de trabajo, a veces los capítulos no seguían el itinerario previsto, y un capítulo traducido más literalmente acababa en manos del director más creativo, con la consiguiente protesta y necesaria corrección del ajuste. Si el espectador es consciente de la existencia de estos dos estilos de doblaje en los capítulos de Profilage es algo que escapa al objetivo del presente estudio. Sirva, sin embargo, la anécdota para subrayar el importante papel que juega el traductor en asegurar la coherencia del producto final, especialmente en proyectos masivos como el descrito, en el que la intervención de distintos agentes puede conllevar, lógicamente, desajustes e incoherencias que pueden pasar fácilmente desapercibidos. Al respecto, destacamos dos aspectos en los que las traductoras velaban por mantener la coherencia a lo largo de los más de cincuenta episodios.

\section{Nombres de los personajes}

Cada traductora se encargaba de los episodios pares o impares, por lo que normalmente se informaba al resto del equipo de trabajo del avance de la trama. Una de las cuestiones que tiene mayor trascendencia en cuanto al trabajo del traductor es la denominación de los personajes. En cuanto a los protagonistas, desde un principio se consensuó entre todos los agentes intervinientes en el proceso de traducción los nombres que se les asignaban. Sin embargo, a veces sucedía que un personaje que en principio no parecía tener mayor protagonismo en un episodio volvía a aparecer en otros o empezaba a cobrar protagonismo. Es el caso de Roze, al que se designó como «DETENIDO» en el episodio 44, ya que ni siquiera en el propio episodio en su versión original se conocía su nombre; sin embargo, a partir del episodio 45 y siguientes se le denominó por su apellido, que en el guion se consignó como «ROZE», ya que se intuía que iba a convertirse en un personaje esencial en la trama, como al final resultó ser. Por tanto, no solo se consensuó en el equipo de trabajo, sino que además se avisó al estudio de doblaje, ya que, como sabemos, se debía contar con la misma voz para el mismo personaje, por lo que era esencial que en las convocatorias que el estudio organiza con cierta antelación se tuviera en cuenta este hecho. Se corrobora de esta forma la función del traductor como garante de la coherencia textual, por una parte, y fuente esencial de información para la organización del trabajo en el estudio, por otra, ya que en el caso de no avisar al estudio o no ser coherentes en la designación de los personajes, el estudio no realizaría correctamente las convocatorias, con la subsiguiente pérdida de tiempo y de dinero.

\section{Tratamientos}

En francés, normalmente se emplea el tu en las relaciones familiares o afectivas muy directas, o para dirigirse a personas conocidas o desconocidas, pero en este último caso siempre que no 
tengan más de unos veinte años. Sin embargo, en los comercios, en la administración, en lugares públicos, para dirigirse a personas mayores o que no se conozcan, o la primera vez que se llega a un puesto de trabajo, aunque los compañeros sean de la misma edad, se emplea el vous. El empleo del vous, por tanto, está más generalizado que el usted en español que, como sabemos, se emplea cada vez con menos frecuencia y en situaciones comunicativas muy acotadas. En el caso de Profilage, los personajes principales de la serie, a pesar de ser compañeros de trabajo durante más de cinco temporadas, siguen empleando el vous para dirigirse entre ellos. Para su traducción en el doblaje, fue necesario adaptar el estilo al público español. La audiencia meta no entendería que compañeros de trabajo que conviven más de ocho horas juntos y que comparten situaciones dramáticas tanto en el plano profesional como en el personal no se tutearan, por lo que se decidió que, una vez la protagonista se integra totalmente en la nueva comisaría de policía, los personajes se hablarían de tú. Esto contribuía a acercar más a los personajes a la audiencia española, y también dotaba de mayor naturalidad al guion de doblaje. Esta toma de decisión se comunicó por escrito a todos los agentes intervinientes en el proceso, para mantener la coherencia a lo largo de la serie.

\section{La pseudo-cientificidad del crime proc}

La serie Profilage presenta unas dificultades para el doblaje particulares porque, entre otras razones, encierra tipologías textuales diversas. Recordemos que la protagonista de la serie, Chloé Saint Laurent, es una criminóloga francesa que se integra en un equipo de investigación de una comisaría, teniendo como compañeros a policías y un médico forense. En cada episodio, los protagonistas deben investigar un

crimen, por lo que deben interactuar entre ellos. En ocasiones, Saint Laurent conversa con un médico forense, en otras con jueces, abogados, fiscales, agentes de policía o psiquiatras y psicólogos, por lo que la presencia de terminología específica y corrección técnica supusieron un verdadero reto para las traductoras. Como sabemos, las conocidas como «lenguas de especialidad» o «lenguas con fines específicos» se caracterizan por una densidad terminológica notable, ya que normalmente su finalidad es transmitir información especializada a especialistas en la materia o a no especialistas pero que tienen un especial interés en ello (por ejemplo, cuando Chloé habla con un forense). Tal y como manifiesta Gamero (200r: 24), el empleo de una lengua de especialidad «obliga al traductor a adquirir una serie de conocimientos sobre el campo temático correspondiente y a dominar la terminología específica y son estos elementos comunes a todas las traducciones especializadas». Con una salvedad: y es que, a pesar de que Profilage es una serie en la que convergen al menos tres lenguas de especialidad distintas (Derecho, Medicina y Psicología), no hay que perder de vista que se trata de un programa de entretenimiento, no un documental, por lo que la naturalidad en los diálogos constituía una prioridad absoluta. Distintas estrategias fueron adoptadas por los equipos de trabajo, y pasamos a comentarlas en los apartados siguientes.

Integración de un especialista en Derecho en el equipo de trabajo

La presencia de un especialista en los equipos de trabajo, como parte activa en la elaboración de la traducción, contribuyó a facilitar la comprensión de algunas cuestiones técnicas relativas a derecho francés. Uno de los ejemplos más claros fue la presencia de palabras polisémicas, muy frecuentes en el lenguaje jurídico. La polisemia 
consiste en que una sola unidad léxica pueda tener o transmitir un abanico de significados (Alcaraz Varó y Hughes, 2002: 8I), más o menos relacionados entre sí (Hernando Cuadrado, 2003: 67). Para determinar la traducción más adecuada en cada caso, era necesario determinar el contexto en el que se empleaba dicho término. Es el caso de plainte, que puede traducirse de numerosas formas: une plainte es una denuncia que se realiza ante un agente de seguridad o en una comisaría y para la que, de forma general, no se necesita abogado. Sin embargo, cuando en la escena interviene un abogado, entonces podríamos estar ante una demanda (característica del orden civil) o una querella (propia de la jurisdicción penal). En estos casos, el experto en derecho era el encargado de lanzar la propuesta que terminológicamente era la más adecuada. Sin embargo, en muchos casos, los directores de doblaje sacrificaban dicha propuesta y la cambiaban por una menos correcta técnicamente pero más cercana a las expectativas del espectador de crime proc. Es decir, preferían una opción que sonara más natural y menos jurídica en aras a facilitar la comprensión del espectador, algo que comentaremos en el apartado 6.2.3.

Otra dificultad que presenta el lenguaje jurídico es la ausencia de equivalencia de determinadas figuras propias de un determinado sistema de derecho. Así determinados cargos o instituciones propias de la organización interna del estado francés no existen como tales en España. Es el caso de gardien de paix, figura que se creó en el siglo XIX en Francia, que pertenece al Cuerpo Nacional de Policía y que se encarga de velar por la seguridad. La equivalencia en cuanto a la función de este cargo sería la de policía local, aunque la traducción más exacta sería la de "gendarme», lo que además permitiría dotar al texto meta de cierto color local, ya que de la estética de la serie así como de los emplazamientos de la misma, se deduce fácilmente que estamos en París. No obstante, en este caso en concreto, se optó por una estrategia domesticante, siguiendo una vez más las instrucciones del director de doblaje encargado de este capítulo, y se optó finalmente por «policía local». Entendemos que se trata de una traducción adecuada, aunque no debemos olvidar que estamos ante la elaboración de un guion de doblaje, por lo que la imagen cumple un papel primordial en el mismo, y la presencia del uniforme del gardien de paix parece que desentona con el título que se le ha otorgado en el doblaje español.

Lo mismo ocurre con Brigade des moeurs, cuerpo de la policía francesa que se encarga de velar por la moralidad, persiguiendo delitos como prostitución, proxenetismo, tráfico de drogas, contrabando de alcohol o pornografía. En España no existe un organismo equivalente, por lo que finalmente se optó por «sexuales» en lugar de «brigada de delitos sexuales», algo que se adecuaba al contexto del capítulo en concreto y que además respondía a la deseada «oralidad prefabricada».

Otro ejemplo significativo fue el de un hombre cuyo estado se describe como en interdit bancaire. En este caso, se trata de una figura de derecho bancario francés que, de nuevo, no existe en España: cuando en Francia una persona emite un cheque sin fondos, el banco establece que esa persona está en situación de interdit bancaire, es decir, no puede emitir cheques. En general, la consecuencia que se deriva inmediatamente es el bloqueo de su cuenta bancaria. La traductora optó por algo más literal, «se encuentra en interdicción bancaria», algo que no suena natural en España, y podría producir confusión en el espectador. Por ello, la ajustadora lo comentó con el experto en derecho para intentar encontrar una traducción más funcio- 
nal. En ese sentido, el término más aproximado al concepto que encierra interdit bancaire sería un «bloqueo de cuenta preventivo», aunque finalmente se decantó por «le embargaron la cuenta» por una cuestión de límite de tiempo impuesto por el doblaje. Una vez más, técnicamente no es la traducción correcta; sin embargo, entendemos que en este caso se trata de una traducción adecuada ya que consigue transmitir la situación real del personaje.

\section{Elaboración de un glosario consensuado}

Considerando que las traductoras eran las primeras en encontrarse con las dificultades terminológicas que presentaba el texto origen, eran ellas las que presentaban una propuesta de traducción, a la que las ajustadoras daban el visto bueno atendiendo al tiempo disponible. Los términos más científicos, al ser, por lo general, unívocos, no presentaban grandes dificultades de traducción. En la mayoría de ocasiones, se ofrecía una traducción literal que, además, se ajustaba a los tiempos, atendiendo a la proximidad de las lenguas francesa y española: así, encontramos tecnicismos como blefaroplastia de párpados, genioplastia, hemorragia cerebral, traumatismo craneal, hueso hioides, hepatitis, laceración, cirugía, autopsia, dolores post-operatorios, análisis toxicológico, análisis entomológico, etc., propios del ámbito médico, para los que se consultaron diccionarios bilingües online. En el ámbito de la psicología, tampoco se presentaron especiales dificultades léxicas: mitómano, tensión psíquica, depresión, narcisista, psicosis afectiva, erotómano, dependencia afectiva, amnesia psicógena, etcétera.

No obstante, los términos pertenecientes al ámbito jurídico presentaron numerosas dificultades por las cuestiones expuestas anteriormente. Es por ello por lo que, en

muchas ocasiones, el experto no solo era el que proponía el término apropiado, sino que además proporcionaba una explicación de lo que implicaba el término francés, para poder dar con el término más adecuado en cada caso. Así encontramos términos del ámbito jurídico como agresión sexual, homicidio, asesinato, víctima, sospechoso, delito de tráfico de drogas, delito de amenazas, antecedentes penales, agresor, etc. Es necesario señalar que los tecnicismos no abundan en esta serie atendiendo al público meta, aficionado al crime proc, pero no necesariamente experto en derecho, medicina forense o psiquiatría forense.

Para la elaboración del glosario, como hemos indicado, las traductoras realizaban la propuesta, que corroboraban o desechaban las ajustadoras. No obstante, los directores de doblaje eran los que siempre tenían la última palabra, por lo que la solución que finalmente se había adoptado en el estudio de doblaje era la que se incluía en el glosario, para adoptarla si volvía a aparecer. Eso sí, el feedback del estudio llegaba siempre con cierto retraso respecto a la labor de traducción. Esta organización del trabajo corrobora que el proceso traductológico en este proyecto se llevó a cabo en un continuo movimiento de ida y vuelta, en el que todos los agentes intervinientes en el proceso estaban en constante comunicación y la retroalimentación se erigía como elemento esencial del proceso.

El ajuste y la oralidad prefabricada: el peso de la tradición representado por el director de doblaje y el ajustador

Como hemos visto hasta ahora, Profilage es una serie que presenta unas dificultades muy específicas a la hora de su traducción, por lo que estimamos resulta interesante explicar cómo se llevó a cabo el proceso en todas sus fases, es decir, desvelar lo que Richart (20I2: 52) denomi- 
na «la caja negra del doblaje [entendida como] un archivo oculto a la mirada del especialista y del público en general».

Para entender la intervención real de los directores de doblaje de esta serie, es necesario remontarnos a las condiciones del encargo. En él se determinó explícitamente que no se requería ajuste con los códigos habituales, sino simplemente que se indicaran los respectivos códigos de tiempo. Por tanto, es de suponer que, o bien era el estudio el encargado de indicar los códigos de isocronía, o bien prescindían de ellos. En cualquier caso, parece evidente que esta decisión jugaría un papel fundamental en el producto final obtenido, ya que la creatividad y el trabajo de los actores de doblaje y de los directores serían, sin duda, mayor que si se contara con un texto en el que se dispone de dichos códigos. Asimismo, cabe resaltar que, en este proyecto las funciones de los distintos agentes intervinientes estaban muy determinadas y se adaptaron a las demandas del estudio.

La oralidad prefabricada implica que el traductor deberá emplear una serie de recursos para conseguir un lenguaje real, natural, en el texto meta. Como sabemos, a las restricciones propias del doblaje se suman otras, que normalmente derivan de recomendaciones de estudios de doblaje, y que son fruto de la normalización lingüística y estilística. Según Ávila (I997: 25-26):

[...] el lenguaje estándar es el arma que aconsejan los ajustadores de diálogos. La utilización de diálogos claros, sencillos, cotidianos, donde tecnicismos y barroquismos sólo tengan cabida por exigencias del guion, conseguirán la empatía que necesita el espectador para creer lo que se está oyendo.

Como ya hemos visto en 6.2.2.I, por exigencias del guion, el texto meta presentaba numerosos tecnicismos. No obstante, también debemos señalar que, en ocasiones, los diálogos de los personajes principales se mantenían con delincuentes, prostitutas, marginados sociales o enfermos mentales. Por tanto, el cambio de registro también constituía una dificultad añadida, pasando de un lenguaje especializado, cargado de tecnicismos, con un estilo depurado, correcto y profesional, a un lenguaje común o incluso al empleo del argot. En estos casos, era fundamental intentar conseguir un estilo natural. Pero al mismo tiempo, el equipo de traducción se encontró con un problema de otro orden: cuando el proyecto empezó a cobrar forma, el equipo de traducción no sabía el horario en el que iba a emitirse la serie, por lo que las traducciones eran bastante fieles al original. Es necesario tener en cuenta que la serie se emitía en prime time en Francia, a las $20.55 \mathrm{~h}$ en la cadena más importante tfr. La serie ha llegado a alcanzar 8 millones de espectadores y un 3I \% de share según la propia cadena, ${ }^{7}$ por lo que era probable que la serie en España se emitiera en un horario similar. Sin embargo, al comunicar el estudio de doblaje que la hora de emisión de Profilage en España sería a las ig.oo h en la 2 del grupo Radio Televisión Española, el equipo de trabajo tuvo que esforzarse en rebajar notablemente el nivel de insultos, lo cual en ocasiones era difícil por la presencia de delincuentes en la serie que empleaban este tipo de lenguaje soez y cargado de palabras malsonantes. Precisamente, la oralidad prefabricada imponía el empleo de determinados insultos; pero el condicionante del horario de emisión obligaba a cambiar el resultado, ya que la cadena se exponía a eventuales sanciones.

7 Véase [http://www.groupe-tfr.fr/en/press-release/ activit\% $\mathrm{C}_{3} \% \mathrm{~A}_{9}$-du-groupe-d $\% \mathrm{C}_{3} \% \mathrm{~A}_{9}$ veloppement-acquisition-cession-diversification/tfi-internation-o], consulta del I8/07/2017. 
Por otra parte, el francés se caracteriza por el empleo sistemático de siglas en la lengua oral, que presentaban obviamente tres dificultades: primero, la comprensión de su significado, lo cual en ocasiones no era fácil, en segundo lugar, encontrar una equivalencia en lengua meta, si la había en siglas (ivg, interruption volontaire de la grossesse; gign, Groupe d'Intervention de la Gendarmerie Nationale; dcri, Direction Générale de Sécurité Intérieure; rg, Renseignements Généraux, rtt, réduction du temps de travail, dpj, Direction Génerale de la Police Judiciaire de Paris, iml, Institut Médico-Légal, etc.); y en tercer lugar, la restricción del ajuste. La dicción de una sigla en francés supone, como regla general, un máximo de tres sílabas. Sin embargo, las siglas carecían de idénticas equivalencias en español. La estrategia que se adoptó fue optar por una equivalencia funcional (dpj: comisaría; dcri: Servicios Secretos); en otros casos, el equipo de traducción se decantó por una equivalencia efímera (Renseignements Généraux por La Secreta), a sabiendas de que la traducción no era precisa (ya que Asuntos Internos sería el equivalente apropiado) pero en este caso las restricciones de tiempo jugaban en contra de la precisión terminológica. La misma solución se observa en cuanto a las siglas iml, correspondiente a Institut Médicolégal que, dependiendo del espacio de que se disponía quedó en algunas ocasiones como «morgue» o en otras como Instituto de Medicina «legal», que es el equivalente acuñado correspondiente. En todos estos casos, eran las ajustadoras las que tenían la última palabra y decidían, de conformidad con el tiempo de que disponían.

Otro de los quebraderos de cabeza para las traductoras fueron las apócopes. El lenguaje oral francés se caracteriza por apocopar, es decir, acortar numerosas palabras, no solo

pertenecientes al lenguaje común (aprem por après-midi, à tout por à tout à l'heure, resto $u$ por restaurant universitaire, d'ac por d'accord), sino también en las lenguas de especialidad que aparecen en la serie (le proc por le procureur, que vendría a ser el fiscal; une perquis por perquisition, es decir, un registro; la psy por psychologue, es decir, la psicóloga, le labo por le laboratoire, es decir el laboratorio, etc.). A la dificultad terminológica había pues que añadir la dificultad en cuanto al ajuste, ya que de una sílaba solía pasarse en general a más de tres, por lo que la labor de ajuste en estos casos era complicada. Por esta razón, de forma general, puede afirmarse que tanto en la traducción como en el ajuste de Profilage se tendió a hacer un esfuerzo de síntesis importante, eliminando sobre todo interjecciones, precisamente para dar cabida a un texto de por sí muy denso.

Por último, es necesario destacar el papel fundamental que desempeñaron los directores de doblaje respecto a la conformación de la jerarquía policial de la comisaría en la que se desarrolla la acción de Profilage. Allí vemos al personaje de Lamarck, que es el commissaire en francés; sus subordinados son Pérac (temporadas I y 2) y Rocher (temporadas siguientes), cuyo cargo es el de commandant. Para proceder a la traducción de los puestos no se realizó una traducción literal, que hubiese sido lo lógico; si Lamarck era el comisario (traducción que se respetó), Rocher y Pérac serían subcomisarios o comandantes; sin embargo, en este caso, el estudio de doblaje consideró que la traducción más adecuada era la de inspector, atendiendo a la presencia de este tipo de personajes en las conocidas crime proc de éxito en España (csi, El Mentalista, Castle, Bones, Ley y Orden, etc.) en las que se les denomina «inspectores». La traducción como «comandante» fue rechazada por sonar muy militar, aunque este mismo argu- 
mento no se empleó para desechar la traducción de lieutenant como teniente, que sí se conservó tal cual.

\section{CONCLUSIONES}

Retomamos en este punto las preguntas de investigación que motivaron el análisis.

- ¿Cómo es el proceso de la traducción audiovisual en el marco de la empresa especializada en la industria actual de la TAV? ¿Cuál es la incidencia de los agentes en el proceso actual de traducción audiovisual?

- ¿Cómo cambian los roles adoptados por los traductores audiovisuales en función del proyecto? ¿Son estos los nuevos perfiles que demanda el sector (un perfil ecléctico y adaptable)?

- ¿En qué consistió, en concreto, un proyecto representativo del género crime proc y de producción francesa como es Profilage, y qué nuevas exigencias profesionales se desprenden de ello?

Como hemos visto a lo largo de estas páginas, en la empresa especializada, la mayor parte de las fases del proyecto de TAV (ver tabla 2) se cumplen. Surge una nueva fase en este proyecto específico que es la adaptación de formato del guion. En Profilage, la traducción es el resultado de los esfuerzos aunados del proveedor de la traducción que, como estructura empresarial, engloba distintos profesionales, algunos no necesariamente vinculados al doblaje (el técnico que convierte archivos .doc a .xls), pero destaca especialmente la incidencia del trabajo en equipo en los resultados y, por consiguiente, el papel de la gestión del proyecto. Los agentes encargados de estas tareas deben ser conscientes de cómo adaptar las funciones de los profesionales a las necesidades del proyecto. En el caso de Profilage, las traductoras tuvieron que funcionar como traductoras, como ajustadoras (sin traducir) y como traductoras ajustadoras, dependiendo de la planificación de las entregas. tual, la gestión, el proceso, la incidencia de las fases y de la interrelación de los agentes en el producto final. Además, ha descrito particularidades del encargo en el plano microtextual y cruces de fases debido a los flujos de actividad en la fase de traducción y restricciones debidas a la oralidad prefabricada, al receptor tipo y al colateral (horario infantil). Sin embargo, no podemos extrapolar estos comportamientos recurrentes en el proyecto descrito al plano de las normas traducción del género. Para poder afirmar que estas decisiones traductológicas se constituyen en normas sería necesario ampliar el corpus de estudio.

Cuando se vuelve a la cadena tradicional, la responsabilidad de darle coherencia al texto recae en el traductor, especialmente si hay dos directores, con gustos diferentes, y poco tiempo para reflexionar sobre la traducción en sala. En las nuevas cadenas que incluyen la figura del traductor adaptador (Ferrer, 20I6: 5I), estos procesos estarían menos atomizados. Sin embargo, el sector no parece decantarse por el uso de traductores ajustadores, sino más bien por diferenciar las dos actividades y que la de adaptación quede reservada a actores, directores de doblaje y ajustadores profesionales, lo que plantea una duda: cuando el volumen de terminología, fraseología específica y recursos propios de una serie es tan grande como para que sea complicado de manejar con las herramientas tradicionales (word, glosarios en Excel), ¿no sería ventajoso recurrir a las herramientas de traducción asistida que hasta ahora se reservaban a la localización? Sin embargo, esto solo puede funcionar en caso de que las versiones 
finales (traducción ajustada) estén en poder de los traductores o traductores adaptadores. Queda en manos de los futuros profesionales 166 de la traducción audiovisual conseguir que el cambio de tendencia hacia un sistema menos atomizado se convierta en una realidad.

RECIBIDO EN ENERO DE 2017 ACEPTADO EN SEPTIEMBRE DE 2018 VERSIÓN FINAL DE SEPTIEMBRE DE 2018

\section{BIBLIOGRAFÍA}

Alcaraz Varó, Enrique y Brian Hughes (2002): El español jurídico, Barcelona: Ariel Derecho.

Ávila, Alejandro (I997): El doblaje, Madrid: Cátedra.

Chaume, Frederic (2003): Doblatge i subtitulació per a la $T V$, Vic: Eumo.

- (2004): Cine y Traducción, Madrid: Cátedra.

- (2005): «Los estándares de calidad y la recepción en la traducción audiovisual», Puentes, 6, 5-I2.

- (2007): «Dubbing practices in Europe: Localisation beats globalisation», Linguistica Antverpiensia, 6, 20I-2I7.

Chaume, Frederic y Cristina García de Toro (2010): Teories actuals de la traductologia, Valencia: Bromera.

- (2012): Audiovisual Translation: Dubbing, Manchester: St Jerome.

Chaves, María Jesús (200o): La traducción cinematográfica. El doblaje, Huelva: Publicaciones de la Universidad de Huelva.

Del Águila, María Eugenia y Emma Rodero (2005): El proceso del doblaje: take $a$ take, Salamanca: Universidad Pontificia de Salamanca.

Chesterman, Andrew (2009): "The Name and Nature of the Translator Studies», Hermes - Journal of Language and Communication Studies, 42, I3-22.

Ferrer Simó, María Rosario (2005a): «Fansub y scanlations: la influencia del aficionado en los criterios profesionales», Puentes, 6, 27-44.

- (2005b): «La actividad del traductor autónomo», en Isabel García Izquierdo (ed.), Experiencias de traducción: reflexiones desde la práctica traductora, Castellón: Publicacions de la Universitat Jaume I.
- (2OII): «Los servicios profesionales de tav: la gestión del proyecto en tres modos audiovisuales», trabajo de investigación [inédito], Castellón: Universitat Jaume I.

- (2OI2): «Los servicios de TAV profesional: pasado, presente y futuro», en Juan José Martínez Sierra (coord.), Reflexiones sobre la Traducción Audiovisual. Tres espectros, tres momentos, Valencia: puv.

- (2016): La gestión de proyectos de traducción audiovisual en España. Seis estudios de caso [Tesis no publicada], Castellón: Universitat Jaume I.

Gamero Pérez, Silvia (200I): La traducción de textos técnicos, Barcelona: Ariel.

Hermans, Hubert J. M. (I996): «Voicing the self: From information processing to dialogical interchange», Psychological Bulletin, II9, 3I-50.

Hernando Cuadrado, Luís Alberto (2003): El lenguaje jurídico, Madrid: Editorial Verbum.

Holmes, James S. (1988): Translated! Papers on Literary Translation and Translation Studies, Amsterdam: Rodopi.

Karamitroglou, Fotios (1999): «Audiovisual Translation at the Dawn of the Digital Age: Prospects and Potentials», Translation Journal, $3 / 3$, http://translationjournal.net/journal/ogav.htm [consulta: 25-05-I8].

- (2000): Towards a methodology for the investigation of norms in audiovisual translation, Amsterdam: Rodopi.

Luyken, Georg-Michael et al. (I991): Overcoming Language Barriers in Television: Dubbing and Subtitling for the European Audience, Dusseldorf: The European Institute for the media.

Mayoral, Roberto (2002): «Nuevas perspectivas dela traducción audiovisual», Sendebar, I4, I07-26.

Martí Ferriol, José Luís (2006): Estudio descriptivo del método de traducción para el doblaje y la subtitulación [Tesis doctoral], Castellón: Universitat Jaume I.

Martínez Sierra, Juan José (20I2): Introducción a la Traducción Audiovisual, Múrcia: Editum.

Pym, Anthony (2009): "Translator training», Proyecto para el Oxford Companion Translation Studies.

Richard Marset, Mabel (20I2): Ideología y traducción: por un análisis genético del doblaje, Madrid: Biblioteca Nueva. 
- (20I3): «La caja negra y el mal de archivo: defensa de un análisis genético del doblaje cinematográfico», TRANS: Revista de Traductología, I7, 51-69.

Torralba, Glòria (20II): «La professió del traductor audiovisual: Descripció sociològica de la tra- ducció per al doblatge», trabajo de investigación [inédito], Castellón: Universitat Jaume I.

Withman-Linsen, Candace (I992): Through the Dubbing Glass: The Synchronization of American Motion Pictures Into German, French and Spanish, Frankfurt am Main: Peter Lang Verlag. 